\title{
Clinical Profile of Brain Tumour in Children
}

\author{
S Sharmin $^{1}$, N Begum ${ }^{2}$, S Khatoon $^{3}$
}

\begin{abstract}
Background: This study was designed to evaluate the clinical profile and location of brain tumours in children so that brain tumour cases could be diagnosed and managed earlier. Materials and Methods: This cross sectional study was carried out from April 2011 to April 2012. A total 50 clinically suspected cases of brain tumour and supported by MRI were enrolled in this study. Results: Brain tumour of children was predominant in male where male to female ratio was almost 1.9:1. Supratentorial and Infratentorial brain tumour were found in $36 \%$ and $64 \%$ cases respectively in children. According to MRI findings in the supratentorial location, craniopharyngioma were commonest $(50 \%)$ followed by cerebral astrocytoma $(22.2 \%)$. In the infratentorial region, medulloblastoma was observed in $(40.6 \%)$, followed by cerebellar astrocytoma $(31.3 \%)$. Vertigo, weakness of limbs were found in $46.9 \%$ and $87.5 \%$ cases respectively in infratentorial group which were significantly $(\mathrm{p}<0.05)$ higher than supratentorial group. Growth failure and behavioral change were found in $16.7 \%$ and $22.2 \%$ cases respectively in supratentorial which were significantly $(p<0.05)$ higher than infratentorial group. Papilloedema, reduced muscle power, increased muscle tone, exaggerated deep reflexes, clonus, gait disturbance and cerebellar signs were significantly $(\mathrm{p}<0.05)$ higher in infratentorial group. Conclusion: Craniopharyngioma and medulloblastoma were more common findings in MRI evaluation in the supratentorial and infratentorial location respectively. Growth failure and behavioral change were found higher in supratentorial than infratentorial group. Vertigo, weakness of limbs, papilloedema, reduced muscle power, increased muscle tone, exaggerated deep reflexes, clonus, gait disturbance and cerebellar signs were higher in infratentorial group. [J Shaheed Suhrawardy Med Coll 2016;8(1): 08-12]
\end{abstract}

Keywords: Brain tumour, supratentorial, infratentorial clinical profile, MRI, children.

\section{Introduction}

Among the childhood malignancies, central nervous system tumours are the most common solid tumour and the second most common malignancy after leukaemia. CNS tumour represent about $20 \%$ of all childhood cancers ${ }^{1}$.The overall annual incidence in the United States of pediatric malignant CNS tumour is about 28 per million children younger than 14 years of age ${ }^{2}$. Another study in Italy showed the incidence of brain tumour was 40 per million children per year ${ }^{3}$. In Sweden a study showed annual incidence of childhood brain tumour was 42 per million children of less than 15 years ${ }^{4}$. Another study in Japan showed age adjusted annual incidence rate of primary intracranial tumour was 36.1 per million children $^{5}$. In India Grover and Hardas reported a frequency of primary brain tumour was $8.2 \%$ in Bombay Cancer Registry ${ }^{6}$.
Khan et al. reported $9.0 \%$ frequency of childhood brain tumour at Pakistan Institute of Medical Sciences, Islamabad, Pakistan $^{7}$. Although children of any age may be affected, children under the age of 15 are more frequently diagnosed with primary brain tumour than those between 15 and 19 yrs old. For all CNS tumours from age 7 to $10 \mathrm{yrs}$, a $40 \%$ drop in the incidence rate was observed, with a slight increase from ages 10 to 12, and a second decline from age 12 to 20 . Another study in Italy showed a higher incidence for boys than girls and it was 45.3 and 34.4 cases per million respectively ${ }^{3}$.

Considering the location, childhood brain tumours are more common in infratentorial than supratentorial location ${ }^{8,9,10}$. Study in Italy showed the most common brain tumour was astrocytomas with an annual incidence was 13.7 per million

1. Dr. Shakila Sharmin, Medical Officer (Paediatrics), National Institute of Cardiovascular Disease.

2. Dr. Nazma Begum, Associate Professor (Paediatrics), Manikganj Medical College.

3. Prof. Soofia Khatoon, Professor of Paediatrics, Centre for Women and child health.

\section{Correspondence}

Dr. Nazma Begum, Associate Professor (Paediatrics), Manikganj Medical College.

Mobile No :01819242374, email: nazmabegum29@ymail.com

Conflict of interest: None

Contributions by authors: All authors contributed in the management of case. Sharmin S involved in Protocol development and data collection. Sharmin $\mathrm{S}$ and Begum $\mathrm{N}$ involved in preparing the article for preparation and Khatoon $\mathrm{S}$ revised the manuscripts.

Financial Support: Self 
children; then 7.0 and 5.8 for medulloblastomas and ependymoma, respectively ${ }^{3}$. Another study showed, for all ages, the incidence of astrocytoma was highest (20 per million) and gliomas had the lowest incidence during infancy (9 per million). Overall ependymoma was the rarest type of brain tumour in children ages 3 to $20 \mathrm{yrs}^{1}$. Presentation of supratentorial tumour varies with different age group. Accelerated head growth, a bulging anterior fontanelle, splayed cranial sutures, developmental delay, loss of developmental milestones, lethargy, vomiting, and failure to thrive may be found with a large tumour, with or without associated hydrocephalus. Infants present with ataxia, vomiting, hemiparesis, headache, visual disturbances, and altered mental status. Older children can communicate and articulate better, and may present with more subtle findings, such as visual problems with blurry vision or diplopia, headaches, and nausea prior to vomiting. They more likely present with seizure from cerebral hemispheric tumour than younger children ${ }^{11}$.

The clinical manifestations of childhood infratentorial tumour are largely those of increased intracranial pressure. Headache is common early symptom. Vomiting and visual disturbances, abnormal gait or in-coordination and focal motor abnormalities are also common symptoms. Drowsiness and stupor are late sign. BP is frequently elevated. Papilloedema, cranial nerves palsy, ataxia, vertigo, and torticollis are other presentation of posterior fossa tumour ${ }^{12,13}$. Very few studies have been done regarding childhood brain tumour in the subcontinent. Especially in our country there is paucity of information about childhood brain tumour and there is no national cancer registry system. This study is thus designed to evaluate the clinical profile, location and histopathological type of childhood intracranial tumour; so that brain tumour cases could be diagnosed and managed earlier and this study will serve as a baseline information for other researchers.

\section{Materials and Methods}

This cross sectional study was carried out from April 2011 to April 2012 in Pediatric department of Shaheed Suhrawardy Medical College \& Hospital, Dhaka Medical College \& Hospital and Bangabandhu Sheikh Mujib Medical University. A total 50 cases were selected purposively. At first all patients were evaluated by detailed history and clinical examination with special emphasis on nervous system. Subsequently MRI of brain was performed in all cases. Cases of doubtful MRI findings were excluded from the study. Those patients who had undergone operation, their histopathological reports were collected. The eventual diagnosis was made by considering the history, clinical profile, MRI findings and histopathology. All these information was collected in a pre-designed structured data collection sheets. All cases of brain tumour in this study described as group I and group II as supratentorial and infratentorial brain tumour respectively. All data were analyzed by using computer based SPSS (version 16.0) programme. Statistical analysis was performed, categorical variables were presented in the form of frequency and percentage and analysis of association was made using chi-square test (2) of significance. Quantitative data were presented in the form of mean and standard deviation. P-value of less $<0.05$ were considered statistically significant. Prior to the commencement of the study informed written consent was taken from each guardian. It was assured that all information and records would be kept confidential and the procedure would be helpful for both the physicians and the patients in making rational approach of the case management.

\section{Results:}

Among 50 cases 33 (66\%) were male and 17 (34\%) were female. Male female ratio was 1.9:1. Majority 26 (52\%) patients were found in 6-10 year group. The mean age was found $7.9 \pm 3.4$ years (Table I). Table II showed MRI findings in different group of patients with brain tumour. Craniopharyngioma was found in $9(50.0 \%)$, cerebral astrocytoma in $4(22.2 \%)$, ependyoma of 3rd ventricle was found in $2(11.1 \%)$ among 18 cases of supratentorial group. Medulloblastoma was found in 13 (40.6\%), cerebellar astrocytoma in $10(31.3 \%)$, 4th ventricle ependymoma in $5(15.6 \%)$ and brain stem glioma was found in $4(12.5 \%)$ among 32 patients of infratentorial group. The table III showed the distribution of different gender of patients by type of tumour. In supratentorial group, craniopharyngiomas and ependymomas of $3 \mathrm{rd}$ ventricle were found equally in male and female patients. Whereas supratentorial cerebral astrocytomas were found more in male than female patients. In Infratentorial group, medulloblastomas, cerebellar astrocytomas, 4th ventricle ependymomas and brain stem gliomas were found more in male than female patients. Majority $45(90.0 \%)$ patients had vomiting, $40(80.0 \%)$ had headache, $33(66.0 \%)$ had visual disturbances, $33(66.0 \%)$ had convulsion and 32 $(64.0 \%)$ had weakness of limbs. Other clinical features were depicted in the table IV. The table V showed the examination findings of the study patients. Papilloedema, reduced muscle power, increased muscle tone, exaggerated deep reflexes, clonus, Gait disturbance, Cerebellar signs were significantly $(\mathrm{P}<0.05)$ higher in group II than group 1. Signs of meningeal irritation, altered consciousness, cranial nerve palsies and extensor planter reflexes were found more in group II than group I, but not statistically significant.

Table I: Distribution of the study patients by age $(n=50)$.

\begin{tabular}{lcc}
\hline Age (in years) & Number of patients & Percentage \\
\hline$\leq 5$ & 13 & 26.0 \\
$6-10$ & 26 & 52.0 \\
$>10$ & 11 & 22.0 \\
\hline Mean \pm SD & 7.9 & \\
Range (min-max) & $(2-15)$ & \\
\hline
\end{tabular}


Table II. Distribution of the study patients by MRI findings $(n=50)$.

\begin{tabular}{lcc}
\hline $\begin{array}{l}\text { MRI findings } \\
\text { Supratentorial }\end{array}$ & $\begin{array}{c}\text { Number of patients } \\
(\mathbf{n = 1 8})\end{array}$ & Percentage \\
\hline Craniopharyngioma & 9 & 50.0 \\
Cerebral Astrocytoma & 4 & 22.2 \\
Ependymoma of $3^{\text {rd }}$ ventricle & 2 & 11.1 \\
Cerebral Gliomas & & \\
Thalamic glioma & 2 & 11.1 \\
Occipital glioblastoma & 1 & 5.6 \\
Infratentorial & $\mathbf{( n = 3 2 )}$ & \\
Medulloblastoma & 13 & 40.6 \\
Cerebellar Astrocytoma & 10 & 31.3 \\
4th Ventricle Ependymoma & 5 & 15.6 \\
Brain Stem Glioma & 4 & 12.5 \\
\hline
\end{tabular}

Table III: Distribution of different gender of the study patients by the types of the tumour $(n=50)$.

\begin{tabular}{|c|c|c|c|c|c|}
\hline \multirow[t]{2}{*}{ Types of the tumour } & \multicolumn{4}{|c|}{ Male $(n=33)$ Female $(n=17)$} & \multirow[b]{2}{*}{ Total } \\
\hline & $\mathrm{n}$ & $\%$ & $\mathrm{n}$ & $\%$ & \\
\hline \multicolumn{6}{|l|}{ Supratentorial } \\
\hline Craniopharyngioma & 4 & 12.1 & 4 & 23.5 & 8 \\
\hline Cerebral Astrocytoma & 4 & 12.1 & 1 & 5.9 & 5 \\
\hline Ependymoma of $3^{\text {rd }}$ ventricle & 1 & 3.0 & 1 & 5.9 & 2 \\
\hline \multicolumn{6}{|l|}{ Cerebral Gliomas } \\
\hline Thalamic glioma & 2 & 6.1 & 0 & 0.0 & 2 \\
\hline Occipital glioblastoma & 1 & 3.0 & 0 & 0.0 & 1 \\
\hline Total & 12 & & 6 & & 18 \\
\hline \multicolumn{6}{|l|}{ Infratentorial } \\
\hline Medulloblastoma & 9 & 27.3 & 5 & 29.4 & 14 \\
\hline Cerebellar Astrocytoma & 6 & 18.2 & 3 & 17.6 & 9 \\
\hline $4^{\text {th }}$ Ventricle Ependymoma & 3 & 9.1 & 2 & 11.8 & 5 \\
\hline Brain Stem Glioma & 3 & 9.1 & 1 & 5.9 & 4 \\
\hline Total & 21 & & 11 & & 32 \\
\hline
\end{tabular}

Table IV: Distribution of the study patients of different groups by clinical features $(n=50)$

\begin{tabular}{cccc}
\hline Clinical features & $\begin{array}{c}\text { Group I (n=18) } \\
\text { n (\%) }\end{array}$ & $\begin{array}{c}\text { Group II (n=32) } \\
\mathbf{n}(\mathbf{\%})\end{array}$ & $\begin{array}{c}\text { P } \\
\text { value }\end{array}$ \\
Headache & $15(83.3)$ & $25(78.1)$ & $0.479 \mathrm{~ns}$ \\
Present & $3(16.7)$ & $7(21.9)$ & \\
Absent & & & \\
Vomiting & $15(83.3)$ & $30(93.8)$ & $0.241 \mathrm{~ns}$ \\
Present & $3(16.7)$ & $2(6.2)$ & \\
Absent & & & \\
Convulsion & $11(61.1)$ & $12(37.5)$ & $0.107 \mathrm{~ns}$ \\
Present & $7(38.9)$ & $20(62.5)$ & \\
Absent & & & \\
Visual disturbance & $13(72.2)$ & $20(62.5)$ & $0.486 \mathrm{~ns}$ \\
Present & $5(27.8)$ & $12(37.5)$ & \\
Absent & & &
\end{tabular}

\begin{tabular}{lccc}
\hline Clinical features & $\begin{array}{c}\text { Group I (n=18) } \\
\text { n (\%) }\end{array}$ & $\begin{array}{c}\text { Group II (n=32) } \\
\mathbf{n}(\%)\end{array}$ & $\begin{array}{c}\text { P } \\
\text { value }\end{array}$ \\
\hline Vertigo & & $15(46.9)$ & $0.010 \mathrm{~s}$ \\
Present & $2(11.1)$ & $17(53.1)$ & \\
Absent & $16(88.9)$ & & \\
Weakness of the limbs & & & \\
Present & $4(22.2)$ & $(87.5)$ & $0.001 \mathrm{~s}$ \\
Absent & $14(77.8)$ & $4(12.5)$ & \\
Growth failure & & & \\
Present & $3(16.7)$ & $0(00)$ & $0.041 \mathrm{~s}$ \\
Absent & $15(83.3)$ & $32(100)$ & \\
Behavioral change & & & \\
$\quad$ Present & $4(22.2)$ & $0(00)$ & $0.013 \mathrm{~s}$ \\
Absent & $14(77.8)$ & $32(100)$ & \\
\hline
\end{tabular}

$\mathrm{s}=$ significant, $\mathrm{ns}=$ not significant

$P$ value reached from chi square test.

Table V: Distribution of the different groups of study patients by examination findings $(n=50)$.

\begin{tabular}{|c|c|c|c|}
\hline Clinical features & $\begin{array}{c}\text { Group I }(n=18) \\
\text { n }(\%)\end{array}$ & $\begin{array}{c}\text { Group II }(\mathrm{n}=32) \\
\text { n (\%) }\end{array}$ & $\begin{array}{c}\mathbf{P} \text { value } \\
0.479 \mathrm{~ns} \\
\end{array}$ \\
\hline \multicolumn{4}{|l|}{ Macrocrania } \\
\hline Present & $1(5.6)$ & $2(6.3)$ & \multirow[t]{2}{*}{$0.708 \mathrm{~ns}$} \\
\hline Absent & $17(94.4)$ & $30(93.7)$ & \\
\hline \multicolumn{4}{|l|}{ Papilloedema } \\
\hline Present & $14(77.8)$ & $31(96.9)$ & \multirow[t]{2}{*}{$0.030 \mathrm{~s}$} \\
\hline Absent & $4(22.2)$ & $1(3.1)$ & \\
\hline \multicolumn{4}{|c|}{ Signs of meningeal irritation } \\
\hline Present & $1(5.6)$ & $8(25)$ & \multirow[t]{2}{*}{$0.085 \mathrm{~ns}$} \\
\hline Absent & $17(94.4)$ & $24(75)$ & \\
\hline \multicolumn{4}{|c|}{ Altered consciousness } \\
\hline Present & $0(0)$ & $5(15.6)$ & \multirow[t]{2}{*}{$0.095 \mathrm{~ns}$} \\
\hline Absent & $18(100)$ & $27(84.4)$ & \\
\hline \multicolumn{4}{|c|}{ Cranial nerve palsy } \\
\hline Present & $10(55.5)$ & $25(78.1)$ & \multirow[t]{2}{*}{$0.094 \mathrm{~ns}$} \\
\hline Absent & $8(44.4)$ & $7(21.9)$ & \\
\hline \multicolumn{4}{|l|}{ Muscle power } \\
\hline Normal & $12(66.7)$ & $6(18.7)$ & \multirow[t]{2}{*}{$0.001 \mathrm{~s}$} \\
\hline Reduced & $6(33.3)$ & $26(81.3)$ & \\
\hline \multicolumn{4}{|l|}{ Muscle tone } \\
\hline Normal & $11(61.1)$ & $7(21.9)$ & \multirow[t]{2}{*}{$0.005 \mathrm{~s}$} \\
\hline Increased & $7(38.9)$ & $25(78.1)$ & \\
\hline \multicolumn{4}{|l|}{ Planter response } \\
\hline Flexor & $0(0)$ & $2(6.2)$ & \multirow[t]{2}{*}{$0.404 \mathrm{~ns}$} \\
\hline Extensor & $18(100)$ & $30(93.8)$ & \\
\hline \multicolumn{4}{|l|}{ Deep reflexes } \\
\hline Normal & $10(55.6)$ & $7(21.9)$ & \multirow[t]{2}{*}{$0.016 \mathrm{~s}$} \\
\hline Exaggerated & $8(44.4)$ & $25(81.3)$ & \\
\hline \multicolumn{4}{|l|}{ Clonus } \\
\hline Present & $1(5.6)$ & $10(31.2)$ & \multirow[t]{2}{*}{$0.034 \mathrm{~s}$} \\
\hline Absent & $17(94.4)$ & $22(68.8)$ & \\
\hline \multicolumn{4}{|l|}{ Gait disturbances } \\
\hline Present & $4(22.2)$ & $28(87.5)$ & \multirow[t]{2}{*}{$0.001 \mathrm{~s}$} \\
\hline Absent & $14(77.8)$ & $4(12.5)$ & \\
\hline \multicolumn{4}{|l|}{ Cerebellar signs } \\
\hline Present & $0(0)$ & $8(25)$ & \multirow[t]{2}{*}{$0.019 \mathrm{~s}$} \\
\hline Absent & $18(100)$ & $24(75)$ & \\
\hline
\end{tabular}

$\mathrm{s}=$ significant, $\mathrm{ns}=$ not significant, $\mathrm{P}$ value reached from chi square test 


\section{Discussion}

This cross sectional study was carried out with an aim to evaluate the clinical profile and the location of the different types of brain tumour. In this study it was observed that more than a half $(52.0 \%)$ of patient's age belonged to 6-10 years of age and the mean age was $7.9( \pm 3.4)$ years with range from 2 to 15 years. Wilne and Ferris have shown in their series, the mean age at presentation was 7.4 years with range from 15 weeks to 17 years ${ }^{14}$, which closely resembled with the current study. Similarly, Mehrazin and Yavari have observed the mean age of the patients at time of diagnosis was $8.8 \pm 3.9$ years and most of the brain tumour $(85 \%)$ occurred in between 5 to 15 years of age $\mathrm{e}^{15}$. In this present study it was observed that brain tumour of children was predominant in male where male to female ratio was almost 1.9:1. Similarly, Ahmed and Wilne observed male to female ratio was 2.5:1 and 4:3 respectively ${ }^{14,15}$. In another study, Mehrazin and Yavari found brain tumour of children more common in male children, where the authors found male to female ratio was $1.4: 1^{16}$. In this study it was observed that infratentorial brain tumour $(64 \%)$ were more common in the children than supratentorials $(36 \%)$. Nayil et al found that $44.75 \%$ were supratentorial and $55.25 \%$ were infratentorial ${ }^{17}$. In another study, Ahmed et al. showed supratentorial in $33.3 \%$ and infratentorial in $66.7 \%{ }^{16}$. Headache, vomiting, visual disturbances, convulsion, neck stiffness and abnormal gait were found in both Supratentorial and Infratentorial brain tumours but no statistical significant $(\mathrm{p}<0.05)$ difference were found between them in this study. On the other hand, vertigo and weakness of limbs were significantly $(p<0.05)$ higher in infratentorial group. Growth failure and Behavioral change were found in $16.7 \%$ and $22.2 \%$ cases respectively in supratentorial which were significantly $(p<0.05)$ higher than infratentorial group. Wilne observed along with headache, vomiting and visual disturbances the other most frequent symptoms and signs for infratentorial tumour were vertigo, weakness of limbs, gait disturbances and altered consciousness. On the other hand for supratentorial tumour seizures, lethargy, behavioral changes, endocrine abnormalities, growth failure and precocious puberty are the more prominent features ${ }^{14}$, which is consistent with the present study. Regarding the examination findings it was observed in this current study that macrocrania, signs of meningeal irritation, altered consciousness, cranial nerve palsy and planter response were almost similar between supratentorial and Infratentorial of the children having brain tumour. On the other hand, Papilloedema, reduced muscle power, increased muscle tone, exaggerated deep reflexes, clonus, gait disturbance and cerebellar signs were significantly $(\mathrm{p}<0.05)$ higher in infratentorial group. Wilne et al. obtained in their study that neurological signs were present at diagnosis in $88 \%$ out of which $38 \%$ had papilloedema, $49.0 \%$ cranial nerve abnormalities, 48\% cerebellar signs, $27 \%$ long tract signs, $11 \%$ somatosensory abnormalities and $12 \%$ had reduced level of consciousness $^{14}$. Apart from features of raised intracranial pressure, motor and visual system abnormalities, macrocephaly, growth failure, and precocious puberty also suggest presence of intracranial tumour ${ }^{14}$. All these findings are consistent with the current study.
According to MRI findings it was observed in this current series that in the supratentorial location, craniopharyngioma were commonest $(50 \%)$ followed by cerebral astrocytoma (22.2\%). In the infratentorial region, Medulloblastoma was observed in $(40.6 \%)$, followed by cerebella astrocytoma (31.3\%). Nayil found the most common tumour in the supratentorial and infratentorial compartments were craniopharyngioma and medulloblastoma respectively ${ }^{16}$, which support the current study.

\section{Conclusion}

The paediatric brain tumour was found to be predominant in 5-9 years age group and more common in male children. The incidence of infratentorial brain tumour was more frequent than supratentorial one. Craniopharyngioma and medulloblastoma were more common findings in MRI evaluation in the supratentorial and infratentorial location respectively. Headache, Vomiting, Visual disturbances and convulsion almost consistent between supratentorial and infratentorial group. However, vertigo and weakness of Limbs were significantly higher in infratentorial group. Papilloedema, reduced muscle power, increased muscle tone, exaggerated deep reflexes, Clonus, Gait disturbance, Cerebellar signs, papilloedema, clonus, gait disturbance and cerebellar signs were significantly higher in infratentorial group and others were almost similar between two groups.

\section{References}

1. Gurney JG, Smith MA, Bunin GR. Miscellaneous intra-cranial and intra-spinal neoplasm. J Natl Cancer Inst 2001; 51-63.

2. Bunin G. What causes childhood brain tumour? Limited knowledge, many clues. Pediatr Neurosurg 2000; 32(6):321-326.

3. Farinotti M, Ferrarini M, Solari A, Filippini G. Incidence and survival of Childhood CNS tumour in the region of Lombardy, Italy. J Oxford 1998; 121(8): 1429-1436.

4. Lannering B, Sandstrom PE, Holm S, Lundgren J, Pfeifer S, Samuelsson U. Classification, incidence and survival analysis of children with CNS tumour diagnosed in Sweden 1984-2005. Acta Paediatr 2009; 98(10):1620-7.

5. Makino K, Nakamura H, Yano S, Kuratsu J. Population based epidemiological study of primary intracranial tumour in child. Childs Nerv Syst 2010; 26(8):1029-34.

6. Grover S, Hardas UD. Childhood malignancies in central India. J Nat Cancer Inst 1972; 49:953-8.

7. Khan AB, McKeen EA, Zaidi SHM. Childhood cancer in Pakistan with special reference to retinoblastoma. J Pak Med Assoc 1983;

3:66-9

8. Naidich TP, Zimmerman RA. Primary brain tumour in children. Semin Radiol 1984; 14:100-114.

9. Hanif G, Shafqat S. Morphological pattern and frequency of intracranial tumour in children. J Coll Physicians Surg Pak 2004; 14(3):150-2.

10. Girolami UD, Anthony DC, Prosch MP. The central nervous system. In: Cotran RS, Kumar V, Collins T (eds). Robbins Pathologic Basis of Disease. 6th edition. WB Saunders company, Philadelphia 1999; p 1343.

11. Brain tumour signs. Available from www. Brain tumour signs. com/ brain- tumour-pics(accessed on August 2012)

12. Kuttesch JF, and Ater JL. Brain tumour in childhood. In: Kliegman RM, 
Behrman RE, Jenson HB, Stanton BF. Nelson Textbook of Pediatrics. 18th edition. Saunders, Philadelphia, 2007; p 2128-2137.

13. Wilne S, Koller K, Collier J, Kennedy C, Grundy R, Walker D. The diagnosis of brain tumour in children: a guideline to assist healthcare professionals in the assessment of children who may have a brain tumour. Arch Dis Child 2010; 95:534-539.

14. Wilne SH, Ferris RC, Nathwani A, et al. The presenting features of brain tumour: a review of 200 cases. Arch Dis Child 2006; 91:502-506.
15. Ahmed N, Bhurgri Y, Sadiq S, Shakoor K.A. Pediatric brain tumours at a tertiary care hospital in Karachi. Asian Pac J Cancer Prev 2007; 8(3): 399-404.

16. Mehrazin M, Yavari P. Morphological pattern and frequency of intracranial tumour in Children. Childs Nerv Syst 2007; 23(2):157-62.

17. Nayil K, Makhdoomi R, Ramzan A, Zahoor S, Rasool M, Wani A et al. Childhood tumour of the brain: demographic pattern over a ten-year period in the Kashmir valley. Pediatr Neurosurg 2011; 47(1): 31-7 